\title{
Evaluating the Blackboard System based on Web Accessibility and Usability Guidelines
}

\author{
Sara Jeza Alotaibi \\ Deanship of Distance Learning, College of Computer Science and Information Technology \\ Taif University \\ Taif, Saudi Arabia
}

\begin{abstract}
In the modern world, every learning organisation needs to be equipped with the latest trends of technology and system so as to ensure they are adept at competing with the rest of the world. Whilst keeping this notion in mind, a new approach for evaluating accessibility and usability for current Learning Management Systems (LMSs) has been proposed. This has been done by presenting various imperative methods for evaluating accessibility and usability for such LMSs. As a case study, this paper provides an attempt at investigating and evaluating the accessibility and usability of the Blackboard System as an example of evaluating LMSs.
\end{abstract}

\section{Introduction}

The invention of the internet and the World Wide Web is one of the most revolutionary of the century. The internet has changed lives, and continues to do so with new technologies being introduced all the time. A new concept that has emerged from the World Wide Web is that of education delivered on the web, referred to as e-learning [1], [2]. E-learning has provided students the opportunity to learn even after school hours. Through such platforms, individuals are able to interact with their teachers and fellow students [3]. In specific consideration to Saudi Arabia, the country has directed its efforts to the field of e-learning, and is being used in several schools and universities [6], [7], [8].

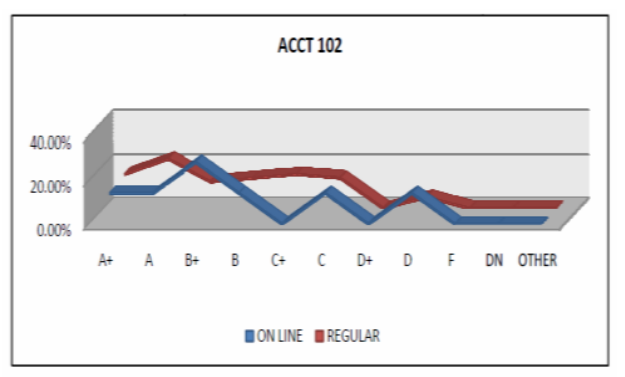

Figure 1:Comparison of performance of online and face-to-face student in ACCT 102 [11]
The following figure details the results of a study carried out by Al-Nuaim [11], in which students have been compared on the basis of their performance when some of them were taught the same content face-to-face and some were taught online.

It is obvious from the figure that, in some instances, students who were taught online outperformed other students for many reasons. One of the popular reasons is applying the accessibility and usability for different users with different needs.

Several problems have been identified through research over the years concerning accessibility and usability evaluations [4]. Later, some tools and methods have been highlighted and proposed by different organisations in an effort to make websites and software applications more accessible and usable. Sloan et al. (2002) [4] proposed a variety of diverse accessibility and usability evaluation methods that have both advantages and disadvantages. Most of these methods cover all accessibility and usability guidelines, established by The World Wide Web Consortium (W3C), Web Access Initiative (WAI), as well as Section 508 guidelines. The W3C Guidelines determined three conformance levels of Web Content Accessibility Guidelines 2.0 (WCAG 2.0), which are A (lowest) ${ }^{1}$, $\mathrm{AA}^{2}$ and AAA (highest) ${ }^{3}$ [5][6].The evaluation for LMSs included the three levels detailed above, and tested the web pages that users are more likely to use in these systems.

This paper is structured in the following manner: Background and Literature Reviews for the current Learning Management Systems (LMSs) are described in Section 2. The various methods of evaluation for follow-up study are listed in Section 3; and the review process, results and discussion are available in Section 4 and Section 5 below.

\footnotetext{
${ }^{1}$ Priority A:disabled users will find it impossible to use some pages

${ }^{2}$ Priority AA: disabled users will find it difficult to use some pages

${ }^{3}$ Priority AAA: disabled users will find it somewhat difficult to use some pages
} 


\section{Background and Literature Reviews for Current LMS}

\subsection{Overview of LMSs}

The following points mention a number of the existing LMSs:

2.1.1.Virtual Class Room CENTRA System. CENTRA is one of the main instruments of the concept of distance education. It is an open interactive medium in which students attend the virtual lectures from the vicinity of their homes or anywhere else, and which accordingly enables direct communication with the instructor. This system is also deployed at East Carolina University [15].

\subsubsection{Electronic Management Educational} System(EMES). EMES is a Learning Management System (LMS), which also aims at enhancing the communication between the faculty and students, thereby promoting collaborative learning and providing course material [12]. Many universities use a similar system around the world, namely University of Leeds [13] and University of Texas [14], for example

2.1.3. Model. This is a Course Management System (CMS), as well as a Virtual Learning Environment (VLE). Moodle is able to replace both EMES and CENTRA since it effectively manages CMS and VLE. Faculty staff can easily add their lectures online by converting existing content into XML and publishing it through the Moodle system [16]. This provides a platform to communicate and collaborate with others, and further enables e-learning accessibility for people with disabilities [16], such as Assignment Submission, Chatting, Surveys, Forum for group discussions, Glossary for courses, Content and assessing learning patterns, Online quizzes, Uploading content, Incorporation of SCORM packages in the courses., Wiki/Blogs/Forums and other tools for peer reviews, E-Assessment, Library resources, Mobile learning, and Audio and video conferencing [17].

Many universities around the world use Model. One of them is University of Saskatchewan, which created an engineering lab course on Moodle. The purpose of this platform was to enable students to collaborate and develop genuine ideas with the help of instructors and different sources of information. A survey was carried out in order to garner students' feedback about the platform; $67 \%$ agreed or strongly agreed with the good performance of Moodle, whilst $30 \%$ were neutral and only 4\% disagreed [20]. In addition, NC State University had the vast majority $(89 \%)$ of their students register on Blackboard for at least one course. They decided to migrate their whole e-learning system to Moodle so that their students could benefit from a greater range of functions and modules. Their students and teachers provided commendable feedback after using Moodle [21]. Importantly, the Moodle System is also deployed at Indian Institute of Technology Bombay [18] and Athabasca University of Canada [19].

2.1.4. Blackboard. Blackboard is an e-learning environment providing a secure and stable platform for communication between teachers and students. It facilitates online collaboration between people present on the platform [21], and offers hundreds of Assessment tools, Mobile learning tools and Plagiarism-detection tools, all complaint with Web 2.0 and providing unique access to course materials and other content [21].However, applying the Blackboard system is very expensive for institutions, and it contains various operational limitations in course development and the displaying of marks. [23]

The Blackboard system is deployed at most Saudi Universities [10], North Carolina Community College System [21] and Blue Ridge Community College [22].

\subsection{Selecting an LMS as a Case Study}

According to the recently published Distance Education Survey Results (2014) by the Instructional Technology Council (ITC), Blackboard acquisitions have overshadowed the Learning Management System (LMS) market over the past nine years (see Table 1).Note that, in the main, those surveyed were the Director of Distance Learning of one of the 345 ITC member institutions or the 1,200 members of the American Association of Community Colleges [24].

Table 1: Learning Management System Usage [24]

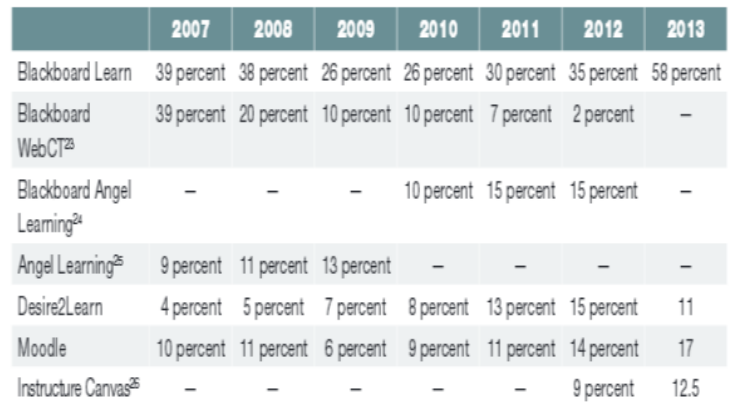

Moreover, following a thorough analysis of the features of LMSs in discussion, it can be concluded that Blackboard seems to be a better choice, offering many more features than other VLEs [10]; therefore, this paper opts to utilise the Blackboard system as a case study for evaluating Accessibility and Usability. 


\section{Designing a New Approach of Evaluation Accessibility and Usability}

Conformance evaluation of web accessibility and usability requires a combination of semi-automated evaluation tools, manual evaluations by experienced reviewers, and studied experience of how people with different disabilities interact with websites by gathering quantitative and qualitative data from representative users performing specific tasks [25]. The following figure shows evaluations tools that are based on all of these methods, and were conducted on March 15, 2015.The Blackboard system applied in Taif University may have changed since this time.

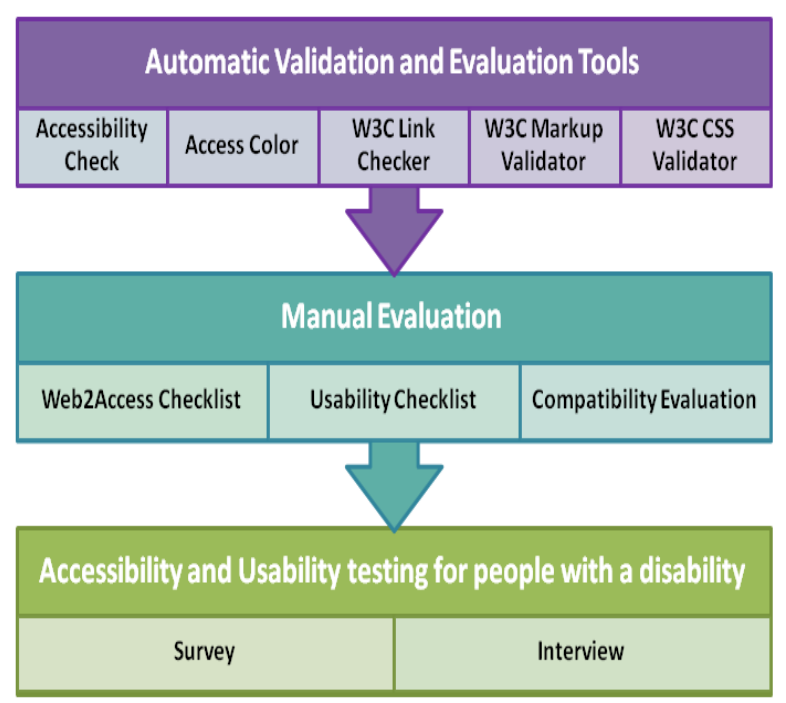

Figure 2: A new approach of evaluation accessibility and usability

\subsection{Automatic Validation and Evaluation Tools}

A large numbers of evaluation tools are available on the W3C Website [26]. The evaluation 'Designing to Standards Evaluation-Online Validation Service' is used by using all applicable validators (only 'Homepage'), which are W3C Link Checker, HTML/CSS Validators, Accessibility Check and AccessColor [26].

\subsection{Manual Evaluation}

There are several steps to performing a manual evaluation, as discussed in the following subsections.

3.2.1. Web2Access Checklist. Web2Access is an interactive website, which has many features, tools and checklists for completing manual evaluations easily [29]. Referring to the Web2Access 11 checklist, which is based on WCAG 2.0, Web
Accessibility Group, JISC TechDis and WebAIM [27],this checklist examines the websites under various settings and conditions, such as:

- Disabling images for alternative text

- Disabling audio for equivalent content

- Disabling scripts, style sheets, frames

- Changing font sizes to ensure readability

- Reducing colour saturation

- Using keyboard only

- Applying different screen resolutions

- Testing text and voice browsers to check equivalent content of graphical browser.

There are tool and program requirements for evaluating, including the AIS Toolbar for Internet Explorer, Web Accessibility Toolbar for Internet Explorer, Firefox, WAVE Toolbar, Accessibar Project Toolbar, Web Developer Toolbar and Illinois Firefox Accessibility Extension for Firefox, Text browser (WebbIE), Screen Reader (Thunder and NVDA), Zoom features, Colour Contrast Analyser and VisCheck

3.2.2. Usability Checklist. Studying the usability of any LMS (only 'Homepage') by testing - Top Ten Guidelines for Homepage Usability [28], this checklist evaluates whether or not the text on the web system is simple, easy and clear for the web system audience.

3.2.3. Compatibility Evaluation. Browsers Shot Website is a website providing screenshots for web pages for different browsers and operating systems [30].

\subsection{Accessibility and Usability Testing for People with a Disability}

Testing can be carried out using online survey software to gather qualitative data that analyses accessibility and usability issues for a broad range of users who are members of these web systems. This survey is divided into two parts and contains a total of seven questions. The first part includes three questions relating to disability and assistive technologies. The other questions test the level of accessibility and usability.

\section{Evaluation Accessibility and Usability for Blackboard System at Taif University}

The Blackboard system applied on the Taif University website is a perfect platform aiming to serve university students and faculty members to communicate with one another easily and quickly. It serves approximately 70,000 students and 3,000 faculty members [10]. 
The tool provides services to faculty members and students, some of which are allowing students to submit their duties, and providing a good communication environment between students and faculty members for each course. Furthermore, faculty members can upload course contents, publish announcement messages, receive and evaluate students' assignments and establish sessions for communicating with students.

\subsection{Review Process}

This section explains the automatic, manual evaluations by using Web2Acess and Usability Checklist.

4.1.1. Automatic Evaluation. As shown in Figure 3, there is 1 problem in Priority A and 5 problems in Priority AA, most of which use 'bgcolor attribute', with most of the web pages not detailing a <title> tag. A deprecated 'bgcolor' attribute is a tag that is no longer supported as part of W3C's latest HTML standard; this means that browsers and assistive technologies are under no obligation to provide support in future versions, thus potentially rendering its contents inaccessible. It is worth noting that many elements and attributes are deprecated solely on the grounds that they cause accessibility problems.

The <title> element is an essential ingredient of usability; it is the only means of recognising a page in a list of search results and bookmark lists, and on the task bar when a browser is minimised. For blind student, it is absolutely crucial because it is recognised as the only reliable means of identifying a webpage from others.

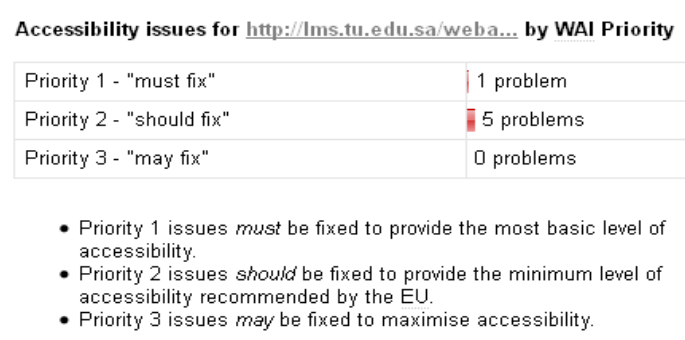

- Priority 1 issues must be fixed to provide the most basic level of accessibility.

- Priority 2 issues should be fixed to provide the minimum level of accessibility recommended by the EU

- Priority 3 issues may be fixed to maximise accessibility.

Figure 3: Accessibility Check Results

AccessColor report shows both colour difference and colour brightness do not meet the recommended standard for $24.62 \%$ of the total text. The results of the W3C Link Checker show that Accessing links has been disabled in link-checker because those entering the Blackboard system need a username and password. There are no errors in CSS according to W3C CSS Validator; however, W3C Markup Validator illustrates that there are 6 errors and 4 warnings, as shown in Figure 4. Most of these errors are recognised as invalid attributes and tags.

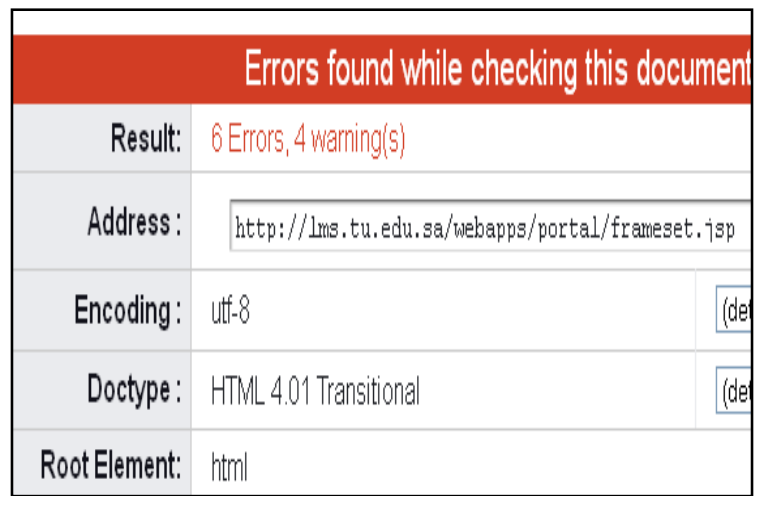

Figure 4: W3C Markup Validator

4.1.2. Manual Evaluation (Web2Access Checklist). The following table provides a summary of the Web2Access Checklist.

Table 2: Web2Access Checklist

\begin{tabular}{|c|c|c|c|c|c|}
\hline Test & 0 & 1 & 2 & 3 & Comment \\
\hline $\begin{array}{l}\text { Built in } \\
\text { accessibility } \\
\text { checks }\end{array}$ & & $\checkmark$ & & & $\begin{array}{l}\text { Main menu system } \\
\text { responds to build in AT }\end{array}$ \\
\hline $\begin{array}{l}\text { Application } \\
\text { works with } \\
\text { External } \\
\text { Assistive } \\
\text { Technologies }\end{array}$ & $\checkmark$ & & & & $\begin{array}{l}\text { Failure with external AT } \\
\text { e.g. screen reader, } \\
\text { keyboard only input, } \\
\text { colour changes. }\end{array}$ \\
\hline $\begin{array}{l}\text { Text or other } \\
\text { alternatives for } \\
\text { image elements. }\end{array}$ & & & $\checkmark$ & & $\begin{array}{l}\text { Alternative text offered } \\
\text { but only as an alternative } \\
\text { to main interactions and } \\
\text { not encouraged in other } \\
\text { areas such as when } \\
\text { loading an image into a } \\
\text { document. }\end{array}$ \\
\hline $\begin{array}{l}\text { Keyboard / } \\
\text { Alternative } \\
\text { input with focus }\end{array}$ & & & & $\checkmark$ & $\begin{array}{l}\text { Keyboard access reaches } \\
\text { information screens or } \\
\text { dialog boxes, keyboard tab } \\
\text { order are good, and focus } \\
\text { is clearly visible with } \\
\text { good descriptions. }\end{array}$ \\
\hline $\begin{array}{l}\text { Labels for } \\
\text { objects, fields or } \\
\text { controls }\end{array}$ & $\checkmark$ & & & & $\begin{array}{l}\text { No labels to guide the } \\
\text { screen reader user. }\end{array}$ \\
\hline $\begin{array}{l}\text { Audio alerts } \\
\text { have visual cues }\end{array}$ & & & $\checkmark$ & & $\begin{array}{l}\text { Alternatives for audio } \\
\text { alerts offer and support } \\
\text { show sounds or sound } \\
\text { sentries. }\end{array}$ \\
\hline $\begin{array}{l}\text { Alternatives for } \\
\text { Video } \\
\text { Animation }\end{array}$ & $\checkmark$ & & & & No alternatives \\
\hline $\begin{array}{lr}\text { Media } & \text { events } \\
\text { offer } & \text { user } \\
\text { control } & \\
\end{array}$ & & & $\checkmark$ & & $\begin{array}{l}\text { The odd /poorly designed } \\
\text { controls but keyboard } \\
\text { accessible. }\end{array}$ \\
\hline $\begin{array}{l}\text { Textual } \\
\text { Information for } \\
\text { screen reader }\end{array}$ & & & & $\checkmark$ & $\begin{array}{l}\text { All aspects of the } \\
\text { application are accessible } \\
\text { and announced by the } \\
\text { screen reader. }\end{array}$ \\
\hline $\begin{array}{l}\text { Keyboard } \\
\text { shortcut keys } \\
\text { offered }\end{array}$ & & $\checkmark$ & & & \begin{tabular}{lr} 
Some & \multicolumn{2}{c}{ instructions } \\
available and shortcut \\
keys work well with \\
standard
\end{tabular} \\
\hline
\end{tabular}




\begin{tabular}{|l|l|l|l|l|}
\hline & & & $\begin{array}{l}\text { shortcuts and assistive } \\
\text { technology. }\end{array}$ \\
\hline $\begin{array}{l}\text { Save user } \\
\text { preferences for } \\
\text { style and zoom }\end{array}$ & & & $\checkmark$ & $\begin{array}{l}\text { Possible to change font } \\
\text { size, style and colour as } \\
\text { well as overall zoom } \\
\text { within the program. }\end{array}$ \\
\hline $\begin{array}{l}\text { Timed events } \\
\text { can be altered }\end{array}$ & & $\checkmark$ & $\begin{array}{l}\text { Option to change times } \\
\text { but poor notification. }\end{array}$ \\
\hline $\begin{array}{l}\text { Change colours } \\
\text { and contrast }\end{array}$ & & $\checkmark$ & $\begin{array}{l}\text { Some changes can be } \\
\text { made to the content when } \\
\text { working with the } \\
\text { application but no } \\
\text { interface changes can be } \\
\text { made other than through } \\
\text { the operating system. }\end{array}$ \\
\hline $\begin{array}{l}\text { Uniform and } \\
\text { standardized } \\
\text { presentation }\end{array}$ & & & $\begin{array}{l}\text { All menus and dialog } \\
\text { boxes etc. are offered in a } \\
\text { manner that is consistent } \\
\text { with known operating } \\
\text { systems. }\end{array}$ \\
\hline $\begin{array}{l}\text { Only a help file once the } \\
\text { application has been } \\
\text { installed. }\end{array}$ \\
\hline Documentation
\end{tabular}

Figure 5 shows that the Blackboard System just support zooming feature. Moreover, it does not support most of the Assistive Technologies such as screen readers. Figure 6 illustrations that there is no labels for dialog boxes. However, the Blackboard System can save user preferences for style and zoom easily as shown in Figure 7. Besides, the menus are very clear and it is compatible with the known operating systems as mentioned in Figure 8.

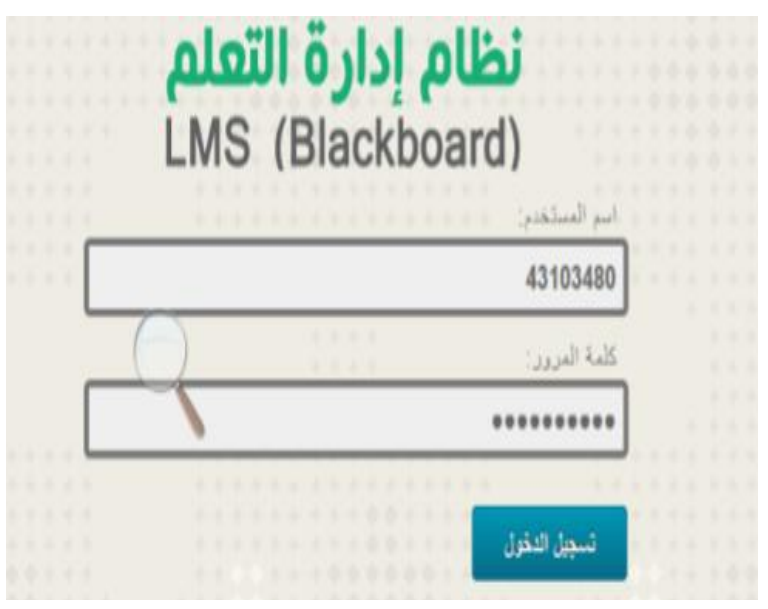

Figure 5: Built in accessibility checks

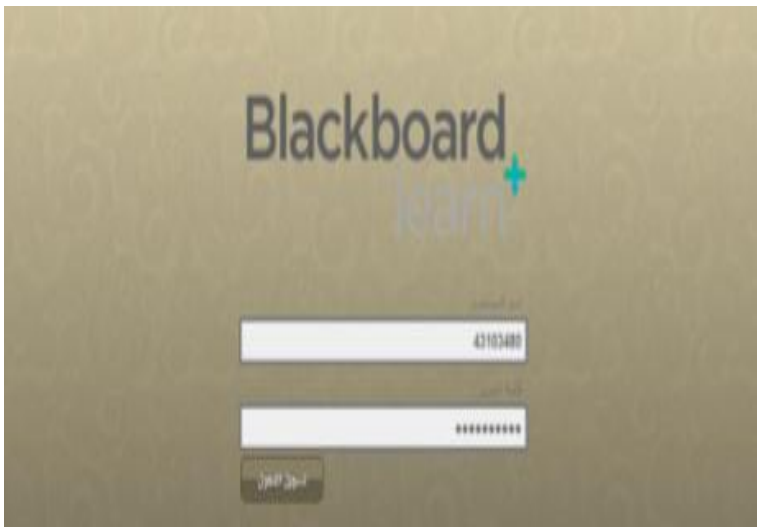

Figure 6: Labels for objects, fields or controls
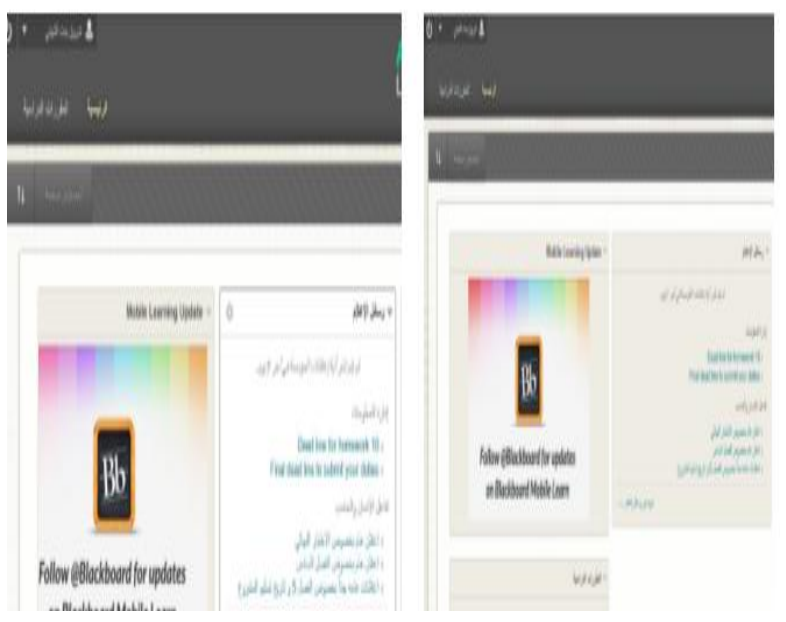

Figure 7: save user preferences for style and zoom

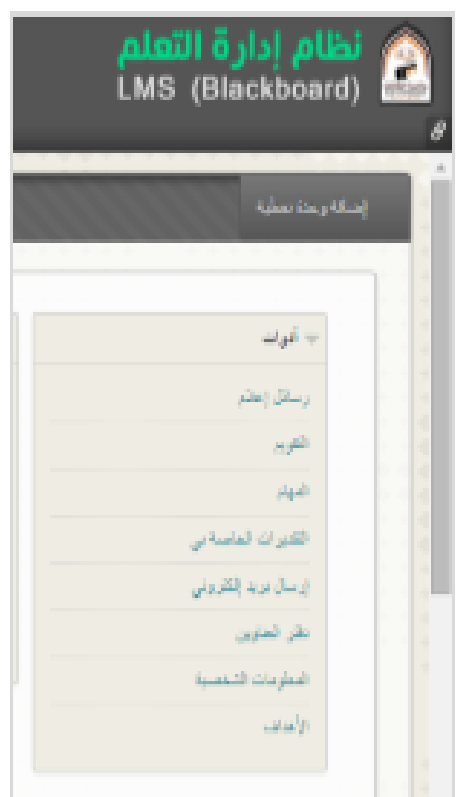

Figure 8: Uniform and standardized presentation 
4.1.3. Manual Evaluation (Usability Checklist). Table 3 shows a summary of Usability Checklist.

Table 3: Usability Checklist

\begin{tabular}{|l|c|}
\hline \multicolumn{1}{|c|}{ Criteiia } & $\begin{array}{c}\text { Yes/ } \\
\text { No }\end{array}$ \\
\hline 1. A One-Sentence Tagline Included & Yes \\
\hline $\begin{array}{l}\text { 2. Well Visible Window Title in search Engines } \\
\text { and Bookmark Lists }\end{array}$ & Yes \\
\hline $\begin{array}{l}\text { 3. Group Corporate Information in One } \\
\text { Distinct Area }\end{array}$ & No \\
\hline 4. Emphasize Site's High-Priority Tasks & Yes \\
\hline 5. Include a Search Input Box & Yes \\
\hline 6. Show Real Site Content Examples & Yes \\
\hline 7. Most Important Key Words as Links & Yes \\
\hline 8. Easy Access to RecentHomepage & No \\
\hline $\begin{array}{l}\text { 9. Don't Over-format Critical Area (like } \\
\text { Navigation Area) }\end{array}$ & Yes \\
\hline 10. Use Meaningful Graphics & Yes \\
\hline
\end{tabular}

\subsubsection{Manual Evaluation (Compatibility}

Evaluation). The Blackboard system has the same results as most browsers and operating systems except Dillo 2.1.1 Browser (with Ubuntu27 Operating System), which shows an error in rendering the top navigation menu [30]. Moreover, there is a problem if the dimensions of the screen are $800 \times 2084$ pixels, in which case users should use the horizontal scrollbar to read page contents.

4.1.5. Testing People with a Disability. A questionnaire was generated for the purpose of gathering feedback from students with special needs concerning the levels of accessibility and usability of the Blackboard System at Taif University. The user survey questionnaire comprised 7 questions, and was made available online. The questionnaire was structured in two parts. Part 1 contains 'Demographic Factors', where the first few questions ask the individual about the type of description he would give himself, i.e. 'person with disability' or 'others'. This question was important in terms of gathering insight regarding the technologies used by people with some disability. Subsequently, a question is asked regarding the level of experience of participants on the internet to judge whether he is a new or experienced one. Part 2 focuses on the criterion of the research study, which are accessibility and usability. This questionnaire tests each area by asking 4 questions, selected according to the theories and guidelines in the respective areas. All of the 4 questions adopted the Likert Scale. The Likert scale is a commonly used approach in questionnaires, concerned with measuring participants' opinions and attitudes regarding a certain statement [9].

A total of 11 people responded of a possible 30 . These participants varied in terms of disability. Owing to the shortage of time, opportunity sampling was adopted as the primary technique to gather participants, i.e. 'whoever was available at the time of the study was included in the sample'[9]. This helped to maximise the number of respondents and thus increase the validity of the findings. This questionnaire is distributed to students who are blind or have low vision in different departments of Taif University with the objective to evaluate the accessibility and usability of the Blackboard System.

The results of the questionnaire show that approximately $100 \%$ of the participants were students with a disability. A total of 50\% of them used assistive technologies, such as Jaws, Screen Magnifier and Screen Reader. The results of the level of experience of participants show that $30 \%$ were experienced, $50 \%$ had intermediate experience, and only $20 \%$ were new on the web. The second question on the questionnaire was a very important one, which helped to evaluate the usability of the Blackboard System. The results show that the highest rank on the sample found that the Blackboard system is difficult to use; however, most of them agree that the Blackboard System had all the information they look for. The last questions inquired into accessibility evaluations, with the results showing that $45 \%$ of the sample finds the Blackboard System accessible by using a form of assistive technologies; however, the same percentage had no opinion regarding the colours and visual design of the system. The results of some questions are given below.

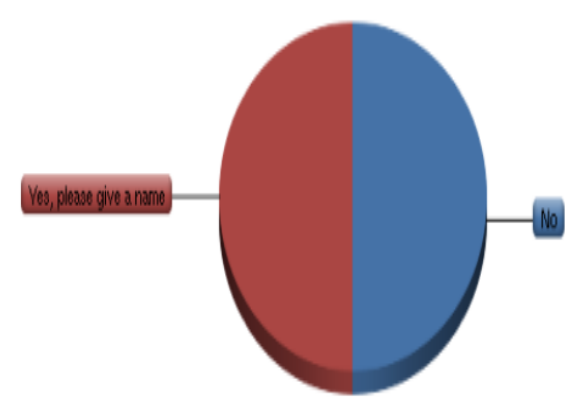

Figure 9: Result of question 2 


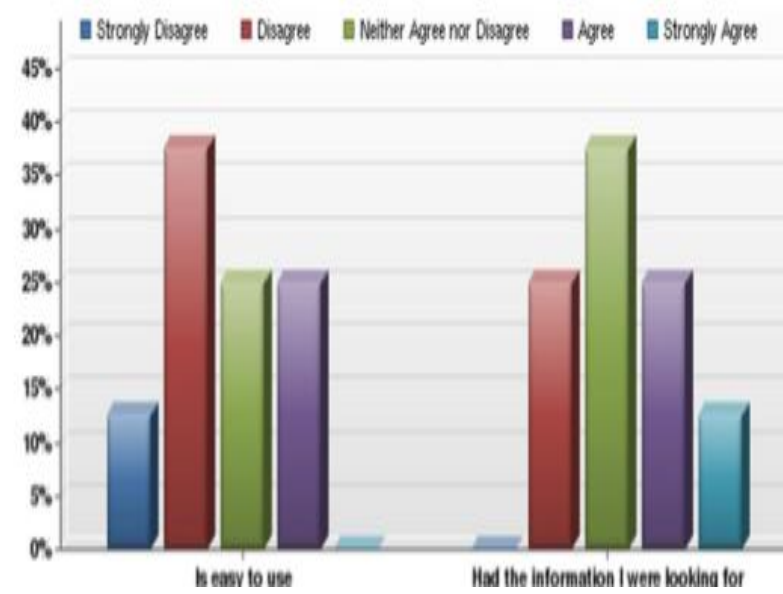

Figure 10: Results of questions 4 and 5

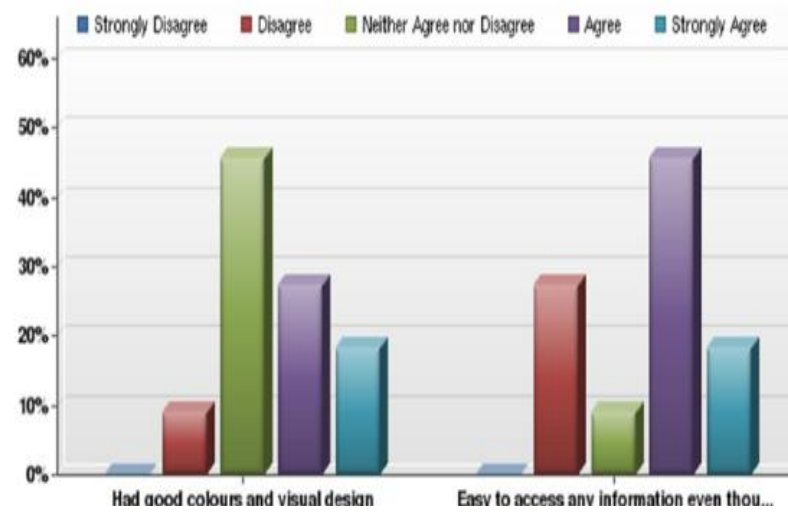

Figure 11: Result of question 6 and 7

\section{Discussion}

This section discusses the accessibility and usability evaluations based on the previous sections.

\subsection{Accessibility Evaluation}

All of the above methods and tools assist with determining the ways in which the Blackboard System does not pass sections of the WCAG Guidelines, which are as follows:

- WCAG1 AA 13.1,WCAG2 A 2.4.4, WCAG1 A 1.1, Section 508 (a), and WCAG2 A 1.1.1 because some tags do not have a link text or an ALT tag, meaning screen readers have nothing to read and therefore have to read out the URL instead. Furthermore, this does not satisfy WCAG2 A F25 because some pages have the same title; therefore, the title cannot be used to distinguish pages.

- WCAG1 A 12.3 and WCAG2 AAA 2.4.10 because each section of content should begin with a heading tag $(\mathrm{H} 1, \mathrm{H} 2, \mathrm{H} 3)$; however, some pages have no heading tags. On the other hand, there are some pages that use headings incorrectly: for example, $\mathrm{H} 2$ appears before $\mathrm{H} 1$, which does not follow WCAG1 AA 3.5 and WCAG2 A 1.3.1.

- WCAG1 A 2.239 and WCAG2 A 1.4.340 due to the fact some pages, especially members' pages, used colors with a low contrast (default style).

- WCAG1 AAA 14.341 and WCAG1 AA 3.342 because it uses more than one style sheet on a page, and it uses a FONT element which makes the pages unaccessible.

\subsection{Usability Evaluation}

The Blackboard System has various usability issues, including FONT styles with a lot of mistakes, such as in the case of underlining to highlight text, which simply makes it confusing for the user as it looks like a link. Therefore, users become frustrated when the 'link' does not work. Moreover, it uses a font size smaller than 12 point. Furthermore, the system uses background images that continuously change colour; as a result, it is difficult for users to read the text in the foreground.

The most common error is that users find it difficult to access anything from the "homepage". Despite the text on this system written simply for a wide audience, it is not organized and uses a lot of generic link labels such as "Read more" which is easily missed by anyone who quickly scans a page. For this, it is important to have sitemap.

\section{Conclusion}

This paper has provided an introduction on learning organisations, discussing the importance of following the usability and accessibility guidelines. It shows a new approach for the evaluation process for learning management systems, and applies these steps of the evaluation process in regard to the Blackboard System utilised at Taif University, considering usability and accessibility. Based on this evaluation, the Blackboard System adopted at Taif University does not meet Accessibility and Usability Guidelines. More details concerning the evaluation will be presented at the conference. This study can be carried out in consideration to other LMSs.

\section{References}

[1] M., Alavi, D., Leidner, "Research commentary: Technology mediated learning-a call for greater depth and breadth of research", Information Systems Research, 12(1), 2001, pg. 1-10.

[2] A., K., Jain, A., Ross, S., Prabhakar, "An Introduction to Biometric Recognition", IEEE Transactions on Circuits and Systems for Video Technology, Special Issue on Image- and Video-Based Biometrics, Vol. 14, No. 1, 2004. 
[3] B.,Adnan, Z., Tasir, "Online Social Learning Model ", IEEE, pp.143-144, 2014.

[4] D., Sloan, P., Gregor, M., Rowan. Accessible accessibility. Proceedings of the CUU First ACM Conference on Universal Usability: ACM, 2000.

[5]P., Windriyani, "Accessibility evaluation using WCAG 2.0 guidelines webometrics based assessment criteria", IEEE, pp.305-311, 2014.

[6] S., M., Alzahrani, N., Salim, J., Bahru, M., "Work in Progress: Developing Arabic Plagiarism Detection Tool for E-Learning Systems", IEEE pp. 105-109, 2009.

[7] A., Alammari," Populating contents of the Saudi eLearning objects repository "Maknaz" from information technology \& knowledge management perspective ", IEEE pp.107-110, 2014.

[8] S., Abahussain, "Implementation of interactive television technology in distance education higher learning program in Saudi Arabia”, Dissertation Abstracts International, 1998.

[9] R. Kumar ," Research Methodology", ISBN 8131304221, APH Publishing, 2007.

[10] M. Alkhattabi, "Blackboard System as an e-Learning Environment: Female students' Perceptions International Journal of Digital Society (IJDS), Volume 5, Issues 1 and 2, March/June 2014.

[11] H., Al-Nuaim, "King Abdulaziz University's Unique Collaborative Approach for Online Undergraduate", 2009.

[12] H., Breuer, R., Konow, N., Baloian, G., Zurita, "Mobile Computing to Seamlessly Integrate Formal and Informal Learning", Seventh IEEE International Conference on Advanced Learning Technologies (ICALT 2007), 2007.

[13] D., Rajaguru, "E-assessment of programming assignments in web service”, IEEE, pp. $484-489,2012$.

[14] University of Texas, "Content Management System", 2007.

[15] CENTRA Saba, "Saba- Case Study", East Carolina University, 2007.

[16]G.,R., Alves, "Student performance analysis under different moodle course designs", $15^{\text {th }}$ International Conference on Interactive Collaborative Learning (ICL), IEEE, pp. $1-5,2012$.

[17] S., Jin," Design of an online learning platform with Moodle", 7th International Conference on Computer Science \& Education (ICCSE), IEEE, pp. 1- 5, 2012.

[18] S., Kumar, S., "A comparative study of moodle with other e-learning systems ", 3rd International Conference on Electronics Computer Technology (ICECT), IEEE, pp. $414-418,2011$.
[19] R., Borromeo, "Online exam for distance educators using moodle", IEEE 63rd Annual Conference International Council for Educational Media (ICEM),IEEE, pp.1-4, 2013.

[20] B., Daku, -Individualized Laboratory Using Moodle, 39th ASEE/IEEE Frontiers in Education Conference, October 18 - 21, San Antonio, TX, 2009.

[21] Yu-Tzu Lin, "Learning-Focused Structuring for Blackboard Lecture Videos", Fourth International Conference on Semantic Computing (ICSC),IEEE, pp.149-155, 2010.

[22] A., Crisp, D., Hutto, -A College-wide Migration Blackboard to Moodle in 6 months, 2007.

[23] N., Lalande, "Blackboard vs. Desire2Learn: A system administrator's perspective on usability " , International Conference on Education and e-Learning Innovations (ICEELI), IEEE, pp.1-4, 2012.

[24] Instructional Technology Council (ITC). 2014 Distance Education Survey Results, 2014.

[25] Rowan, M., Gregor, P., Sloan, D. \& Booth, P." Evaluating web resources for disability access". The Fourth International ACM Conference on Assistive Technologies (ASSETS 2000). Virginia: ACM, 2000.

[26] Zaphiris, P., Kurniawan, S.H. \& Ellis, R.D.” Usability and Accessibility Comparison of Governmental, Organizational, Educational and Commercial Aging/Health-Related Web Sites", WebNet Journal: Internet Technologies, Applications \& Issues 3 (3), 45-52.

[27] WebAIM, "WCAG 2.0 Checklist", [Online] http://webaim.org/standards/wcag/WCAG2Checklist.pdf, 2013 [Accessed: Mar 27,2015].

[28] J., Nielsen, The Ten Most Violated Homepage Design Guidelines [Online] Available: http://www.nngroup.com/articles/most-violatedhomepage-guidelines/, 2003. [Accessed: Mar 27,2015].

[29]Web2 Access, [Online] Available: http://www.web2access.org.uk/ [Accessed: June 27,2015].

[30]Browser Shots, [Online] Available: http://browsershots.org [Accessed: June 27,2015]. 